\title{
Is fusion necessary for thoracolumbar burst fracture treated with spinal fixation? A systematic review and meta-analysis
}

\author{
Juliete M. Diniz, MD, and Ricardo V. Botelho, PhD \\ Department of Neurosurgery, Hospital do Servidor Público Estadual-IAMSPE, São Paulo, Brazil
}

OBJECTIVE Thoracolumbar fractures account for $90 \%$ of spinal fractures, with the burst subtype corresponding to $20 \%$ of this total. Controversy regarding the best treatment for this condition remains. The traditional surgical approach, when indicated, involves spinal fixation and arthrodesis. Newer studies have brought the need for fusion associated with internal fixation into question. Not performing arthrodesis could reduce surgical time and intraoperative bleeding without affecting clinical and radiological outcomes. With this study, the authors aimed to assess the effect of fusion, adjuvant to internal fixation, on surgically treated thoracolumbar burst fractures.

METHODS A search of the Medline and Cochrane Central Register of Controlled Trials databases was performed to identify randomized trials that compared the use and nonuse of arthrodesis in association with internal fixation for the treatment of thoracolumbar burst fractures. The search encompassed all data in these databases up to February 28, 2016.

RESULTS Five randomized/quasi-randomized trials, which involved a total of 220 patients and an average follow-up time of 69.1 months, were included in this review. No significant difference between groups in the final scores of the visual analog pain scale or Low Back Outcome Scale was detected. Surgical time and blood loss were significantly lower in the group of patients who did not undergo fusion $(p<0.05)$. Among the evaluated radiological outcomes, greater mobility in the affected segment was found in the group of those who did not undergo fusion. No significant difference between groups in the degree of kyphosis correction, loss of kyphosis correction, or final angle of kyphosis was observed.

CONCLUSIONS The data reviewed in this study suggest that the use of arthrodesis did not improve clinical outcomes, but it was associated with increased surgical time and higher intraoperative bleeding and did not promote significant improvement in radiological parameters.

https://thejns.org/doi/abs/10.3171/2017.1.SPINE161014

KEY WORDS fusion; thoracolumbar burst fracture; meta-analysis; spinal fracture; arthrodesis; trauma

$\mathrm{T}$ HORACOlumbar fractures account for $90 \%$ of spinal fractures, with the burst subtype corresponding to $20 \%$ of the total. $1,7,8,20$

Thoracolumbar burst fracture was first described in 1963 by Sir Frank Holdsworth as an injury that results from axial loading with or without flexion and dispersion of the vertebral body fragments. ${ }^{3}$ This fracture was considered mechanically stable and treated conservatively. ${ }^{11}$

However, the optimal treatment for this type of fracture is still controversial. ${ }^{16,24}$ Since the 1990 s, the surgical approach has been introduced as a practical treatment option.
Surgery for burst fractures might shorten a patient's hospital stay and hasten mobility and ambulation. ${ }^{14}$

Arthrodesis (fusion) has been used to promote the final biological stabilization of the fracture and to protect the fixation system from material fatigue failure caused by spinal column movement at the fractured site. The failure of the fixation system would be, hypothetically, just a matter of time without the protection of arthrodesis. The need for fusion associated with internal fixation has been questioned in recent studies. , $, 6,12,13,21-23,25$ The aim of this review was to evaluate the effect of arthrodesis on surgi- 
TABLE 1. Baseline characteristics of the studies

\begin{tabular}{|c|c|c|c|c|c|}
\hline Study Characteristic & Wang et al., 2006* & Dai et al., 2009 & Tezeren et al., 2009 & Jindal et al., 2012 & Chou et al., 2014* \\
\hline $\begin{array}{l}\text { No. of patients per group (no- } \\
\text { fusion/fusion) }\end{array}$ & $28: 30$ & $36: 37$ & $21: 21$ & $24: 23$ & $22: 24$ \\
\hline Mean follow-up time (mos) & 41.0 & 72 & 34.6 & 23.9 & 146 \\
\hline Mean age (yrs) & 39.8 & 34.6 & 36.2 & 29.4 & 39.4 \\
\hline Sex (males/females) & $42: 16$ & $56: 17$ & $30: 12$ & $30: 17$ & $34: 12$ \\
\hline Type of fracture & Burst & Burst & Burst & Burst & Burst \\
\hline No. of levels treated & 1 & 1 & 1 & 1 & 1 \\
\hline Denis classification & Predominantly Type B & Type B & Predominantly Type B & $\dagger$ & Predominantly Type B \\
\hline Load-sharing score & $\dagger$ & $\leq 6$ & $\dagger$ & $\leq 6$ & $\dagger$ \\
\hline Type of surgery & Open & Open & Open & Open & Open \\
\hline $\begin{array}{l}\text { No. of levels instrumented, } \\
\text { fusion \& no-fusion groups }\end{array}$ & $\begin{array}{l}1 \text { above } \& 1 \text { below } \\
\text { fracture }\end{array}$ & $\begin{array}{c}1 \text { above \& } 1 \\
\text { below fracture }\end{array}$ & $\begin{array}{c}2 \text { or } 3 \text { above } \& 2 \text { below } \\
\text { fracture }\end{array}$ & $\begin{array}{c}1 \text { above \& } 1 \text { below } \\
\text { fracture }\end{array}$ & $\begin{array}{l}1 \text { above \& } 1 \text { below } \\
\text { fracture }\end{array}$ \\
\hline \multicolumn{6}{|l|}{ Fusion } \\
\hline Technique & Posterolateral & Posterolateral & Posterolateral & Posterolateral & Posterolateral \\
\hline Autogenous bone graft & $\begin{array}{l}\text { From iliac crest, laminae, } \\
\text { \& spinous process }\end{array}$ & From iliac crest & $\begin{array}{l}\text { From iliac crest, laminae, } \\
\text { \& spinous process }\end{array}$ & From iliac crest & $\begin{array}{c}\text { From iliac crest, } \\
\text { laminae, and spinous } \\
\text { process }\end{array}$ \\
\hline Postop bracing duration (mos) & 3 & $\dagger$ & 3 & 3 & 3 \\
\hline
\end{tabular}

* To avoid duplication of results in the same sample of patients in 2 studies (Wang et al. [2006] and Chou et al. [2014]), only 220 patients were included in the final analysis.

$\dagger$ Not described.

cally addressed thoracolumbar burst fractures compared with that of fixation without arthrodesis.

\section{Methods}

For this systematic review, we followed the guidelines of the Preferred Reporting Items for Systematic Reviews and Meta-Analyses (PRISMA). ${ }^{17}$ The search was performed on all data up to February 28, 2016, in the Medline and Cochrane Central Register of Controlled Trials databases. The key words "fusion" or "arthrodesis" and "burst fracture" or "thoracolumbar fracture" or "spinal fracture" were used. We imposed no region, language, or type-of-study restriction. The survey was supplemented by a manual search of spine journals and of the lists of references cited in the selected articles.

This meta-analysis included only randomized and quasi-randomized studies with the following characteristics: patients were older than 18 years, single-level traumatic burst-type thoracolumbar fractures were studied, the study involved a minimum follow-up of 12 months, at least 20 patients were evaluated in each group (fusion/ no fusion), studies were consistent in their description of fixation and fusion techniques, and pre- and postoperative clinical and radiological outcome data were available.

The risk of bias of the selected works was estimated according to guidelines proposed in the Cochrane Handbook for Systematic Reviews of Intervention, ${ }^{10}$ which assess the risk of bias in 7 domains, each scored subjectively as high risk, low risk, or uncertain risk.

The data were grouped as study characteristics (Tables 1 and 2), clinical outcomes, outcomes related to surgery, or radiological outcomes. All stages of this research were conducted independently by 2 investigators. Disagreements were resolved after discussion.

The meta-analysis was performed using Comprehensive Meta-Analysis 2.0 software (Biostat). Dichotomous categorical variables were analyzed by using odds ratios. Continuous variables were analyzed by using mean raw differences. Statistical heterogeneity between studies was calculated using $\mathrm{I}^{2}$ and $\mathrm{Q}$ statistics. Results are reported with their $95 \%$ confidence interval (CI). The significance level was $\mathrm{p}<0.05$. Randomized or fixed-effect meta-analysis was performed, depending on heterogeneity of the data.

\section{Results Literature Search}

The search strategy identified 611 articles in Medline and 767 articles in the Cochrane Central Register of Controlled Trials. From these articles, 12 in the Medline database and 8 in Cochrane Central were selected by title; 5 duplicate items were excluded. The 15 remaining articles selected by title were then evaluated fully. Five studies met the established inclusion criteria; 4 were randomized and 1 was quasi-randomized. One of the randomized trials was suggested to be a long-term follow-up study ${ }^{5}$ based on previous work..$^{25}$ Only data from the last follow-up were considered for a pooled evaluation of the Low Back Outcome Scale (LBOS) ${ }^{9}$ and radiological outcomes (Fig. 1).

\section{Clinical Outcomes}

Visual Analog Pain Scale

The visual analog scale (VAS) for pain was used to an- 
TABLE 2. Characteristics of variables in each study

\begin{tabular}{|c|c|c|}
\hline Outcome \& Study & No-Fusion Group & Fusion Group \\
\hline \multicolumn{3}{|l|}{ VAS score at last follow-up } \\
\hline Chou et al., 2014 & $2.1(0.93)$ & $2.0(0.91)$ \\
\hline Dai et al., 2009 & $1.5(1.3)$ & $1.4(1.5)$ \\
\hline \multicolumn{3}{|l|}{ LBOS score at last follow-up } \\
\hline Chou et al., 2014 & $65.3(6.9)$ & $65.8(6.3)$ \\
\hline Jindal et al., 2012 & $34.92(16.2)$ & $15.2(23)$ \\
\hline Tezeren et al., 2009 & $55.7(10.6)$ & $57.8(8.8)$ \\
\hline Wang et al., 2006 & $66.9(4.4)$ & $65.6(7)$ \\
\hline \multicolumn{3}{|c|}{ Duration of hospitalization (days) } \\
\hline Tezeren et al., 2009 & $10.8(2.8)$ & $10.2(2.8)$ \\
\hline Dai et al., 2009 & $13.0(6.1)$ & $11.9(3.3)$ \\
\hline Wang et al., 2006 & $16.6(6.9)$ & $14.6(10.7)$ \\
\hline \multicolumn{3}{|l|}{ Surgical time (mins) } \\
\hline Tezeren et al., 2009 & $155.7(32.3)$ & $245.2(78)$ \\
\hline Jindal et al., 2012 & $107.5(11)$ & $142.2(27.8)$ \\
\hline Dai et al., 2009 & $102.6(53.4)$ & $152(62.4)$ \\
\hline Wang et al., 2006 & $162(44)$ & $224(63.1)$ \\
\hline \multicolumn{3}{|l|}{ Intraop blood loss (ml) } \\
\hline Tezeren et al., 2009 & $290.4(124)$ & $519(152)$ \\
\hline Jindal et al., 2012 & $378(140)$ & $486.5(175)$ \\
\hline Dai et al., 2009 & $310.4(53.1)$ & $423.7(72.8)$ \\
\hline Wang et al., 2006 & $303(148)$ & $572(367)$ \\
\hline \multicolumn{3}{|l|}{ Segmental motion $\left({ }^{\circ}\right)$} \\
\hline Wang et al., 2006 & $4.8(2.8)$ & $1.0(1.2)$ \\
\hline Chou et al., 2014 & $4.2(1.9)$ & $0.9(1.0)$ \\
\hline \multicolumn{3}{|l|}{ Preop kyphotic angle $\left(^{\circ}\right)$} \\
\hline Tezeren et al., 2009 & $20.9(2.8)$ & $20.0(2.4)$ \\
\hline Jindal et al., 2012 & $16.98(11.7)$ & $18.46(7.4)$ \\
\hline Dai et al., 2009 & $18.7(10.7)$ & $18.2(11.3)$ \\
\hline Wang et al., 2006 & $16.8(6.8)$ & $19.8(8.3)$ \\
\hline Chou et al., 2014 & $16.4(6.6)$ & $19.5(8.1)$ \\
\hline \multicolumn{3}{|l|}{ Postop kyphotic angle $\left({ }^{\circ}\right)$} \\
\hline Tezeren et al., 2009 & $4.7(2.2)$ & $5.1(2.2)$ \\
\hline Jindal et al., 2012 & $4.93(8.7)$ & $5.03(6.1)$ \\
\hline Dai et al., 2009 & $0.5(1.0)$ & $0.6(0.7)$ \\
\hline Wang et al., 2006 & $1.6(5.3)$ & $4.1(6.6)$ \\
\hline Chou et al., 2014 & $1.5(5.3)$ & $4.0(6.5)$ \\
\hline \multicolumn{3}{|c|}{ Kyphotic angle at last follow-up $\left(^{\circ}\right)$} \\
\hline Tezeren et al., 2009 & $7.9(1.5)$ & $7.4(2.2)$ \\
\hline Jindal et al., 2012 & $8.51(9.4)$ & $10.51(6.9)$ \\
\hline Dai et al., 2009 & $1.7(1.3)$ & $1.4(1.6)$ \\
\hline Wang et al., 2006 & $9.8(6.7)$ & $11.5(8.1)$ \\
\hline Chou et al., 2014 & $13.8(6.6)$ & $14.7(7.1)$ \\
\hline \multicolumn{3}{|l|}{$\begin{array}{l}\text { Vertebral body height } \\
\text { correction (\%) }\end{array}$} \\
\hline Tezeren et al., 2009 & $36.0(8.87)$ & $35.5(8.51)$ \\
\hline Wang et al., 2006 & $32.0(11.2)$ & $33.9(10.9)$ \\
\hline \multicolumn{3}{|l|}{ No. of system failures } \\
\hline Tezeren et al., 2009 & 1 & 1 \\
\hline
\end{tabular}

» CONTINUED FROM PREVIOUS COLUMN

TABLE 2. Characteristics of variables in each study

\begin{tabular}{ccc}
\hline \multicolumn{1}{c}{ Outcome \& Study } & No-Fusion Group & Fusion Group \\
\hline No. of system failures (continued) & & \\
\hline Jindal et al., 2012 & 1 & 2 \\
\hline Dai et al., 2009 & 0 & 0 \\
\hline Wang et al., 2006 & 3 & 5 \\
\hline No. of system removals & & \\
\hline Tezeren et al., 2009 & 1 & 0 \\
\hline Dai et al., 2009 & 0 & 0 \\
\hline Chou et al., 2014 & 18 & 9 \\
\hline
\end{tabular}

Values are presented as the mean (SD) unless otherwise indicated.

alyze functional outcomes in 2 studies. The average VAS score at the final follow-up visit was assessed for both groups. The mean difference in VAS pain scores between the groups was 0.1 points $(95 \% \mathrm{CI}-0.31$ to $0.51 ; \mathrm{p}=0.63$; $\mathrm{I}^{2}=0$ ), which did not favor the no-fusion group (result not significant) (Fig. 2).

\section{Low Back Outcome Scale}

Four of the 5 studies described the functional outcomes based on the LBOS. The average LBOS scores for both groups at the final follow-up visit were assessed. This scale consists of 9 factors. The summary effect was 4.03 favoring the no-fusion group (95\% CI -4.97 to $13.05 ; \mathrm{p}=0.38$; $I^{2}=49.37$ ), but it was not statistically significant (Fig. 3).

\section{Outcomes Related to Surgery}

Surgical Time

Four studies evaluated the difference in durations of surgery. Surgical time was significantly shorter in the no-fusion group. The summary effect was -54.9 minutes (95\% CI -77.27 to $-32.65 ; \mathrm{p}<0.05 ; \mathrm{I}^{2}=0$ ) (Fig. 4).

\section{Intraoperative Blood Loss}

Four trials compared intraoperative blood loss. Blood loss was significantly lower in the no-fusion group. The summary effect was $-164.45 \mathrm{ml}(95 \% \mathrm{CI}-236.64$ to $-92.26 ; \mathrm{p}<0.05 ; \mathrm{I}^{2}=6.6$ ) (Fig. 5).

\section{Length of Hospital Stay}

Lengths of hospital stay were evaluated in 3 trials. The summary effect was 0.88 days $(95 \% \mathrm{CI}-0.42$ to $2.17 ; \mathrm{p}=$ $0.18 ; \mathrm{I}^{2}=0$ ), which did not favor the no-fusion group. The benefit of a gain of less than 1 day is questionable. The difference was not statistically significant (Fig. 6).

\section{Outcomes Related to the Fixation System}

\section{Failures of the Fixation System}

Breaking, loosening, bending, and displacement of the screws were considered fixation system failures.

In the 5-7 years of follow-up, no case of system failure was described in the report by Dai et al. ${ }^{6}$ Jindal et al. ${ }^{13}$ reported 2 cases of implant failure 11 and 15 months after surgery in the fusion group and 1 case 7 months after sur- 


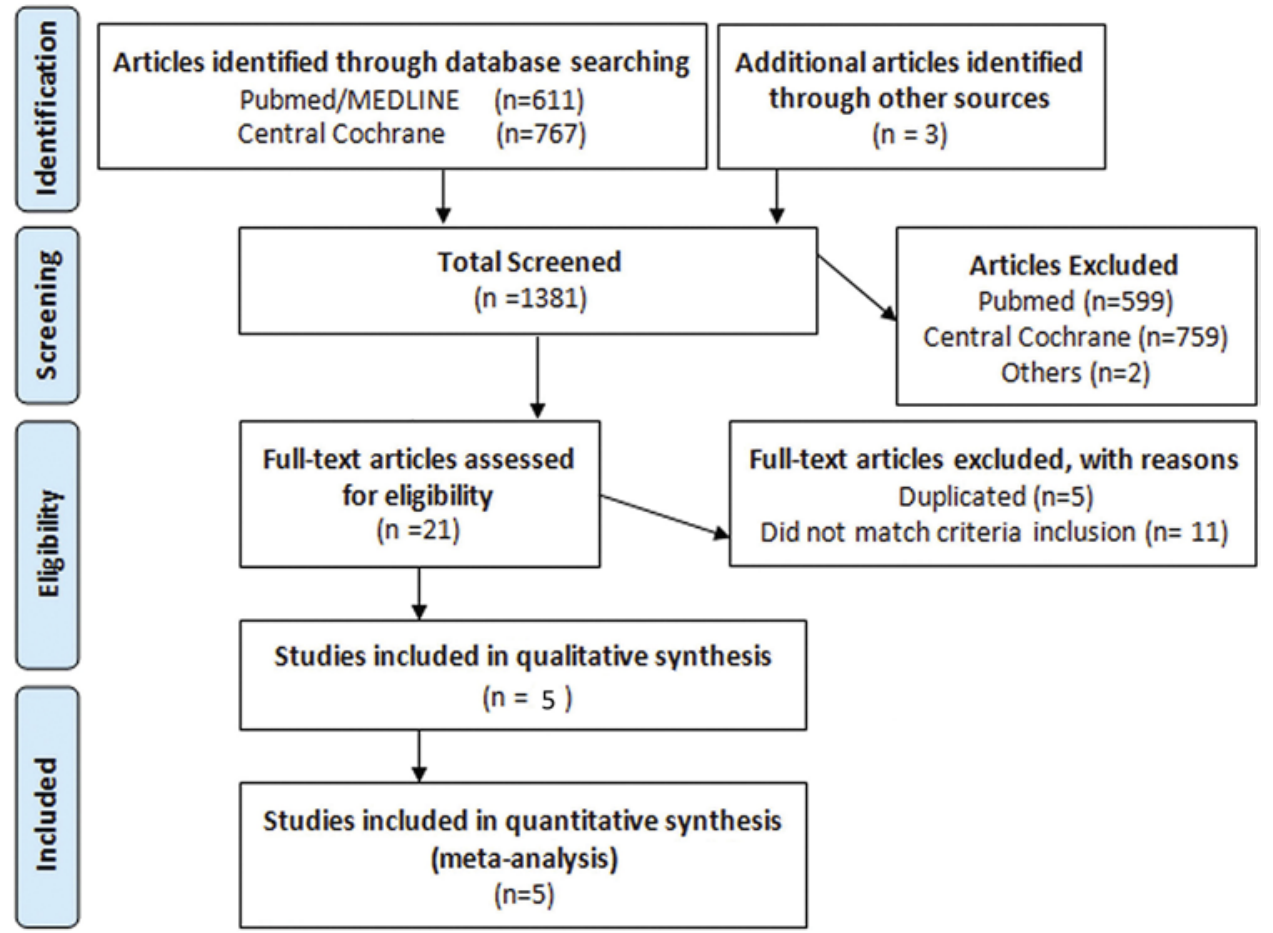

FIG. 1. PRISMA flow diagram for selection of articles in the meta-analysis. Figure is available in color online only.

gery in the no-fusion group. Tezeren et al. ${ }^{22}$ found 1 case in each group in a mean of 34.6 months. In 41 months of follow-up in a study by Wang et al., ${ }^{25} 5$ failures occurred in the fusion group and 3 occurred in the no-fusion group; afterward, no other case was described. ${ }^{5}$ In general, implant failure was not a common adverse event in either of the 2 groups.

The overall incidence of system failure was $5.9 \%$. In the no-fusion group, a total of 5 (4.6\%) faults occurred. In the fusion group, a total of $8(7.2 \%)$ failures occurred. The summary effect was 0.687 (95\% CI 0.211-2.238; $\mathrm{p}=0.53$; $I^{2}=0$ ). The result favors the no-fusion group, but the difference was not statistically significant (Fig. 7).

\section{Removal of the Fixation System}

Removal of the fixation system was defined as the removal of the implant secondary to a complication. The obtained summary effect was 4.09 (95\% CI 0.67-25.02; p $\left.=0.127 ; \mathrm{I}^{2}=0\right)$. These data favor the fusion group (Fig. 8).

\section{Radiological Outcomes}

Mobility in the Fractured Segment

Mobility in the fractured segment was assessed by the angular variation at the level of the fracture using flexion/ extension profile radiographs according to a method described by Mumford et al. ${ }^{18}$ Two studies evaluated mobility in the fractured segment. Both of these studies were performed with the same patient sample. Only the last follow-up data were described. The no-fusion group had a mean $( \pm \mathrm{SD}) 4.2^{\circ}\left( \pm 1.9^{\circ}\right)$ and the fusion group had $0.9^{\circ}( \pm$ $1.0^{\circ}$ ) of segmental motion after 10 years.

\section{Correction of Kyphosis in the Affected Segment}

Kyphosis correction in the affected segment was calculated as the difference between preoperative and immediately postoperative kyphotic angles. Five studies evaluated kyphosis correction. The summary effect was $0.86^{\circ}$ $\left(95 \% \mathrm{CI}-0.37^{\circ}\right.$ to $2.09^{\circ} ; \mathrm{p}=0.17 ; \mathrm{I}^{2}=0$ ) in favor of the no-fusion group, but the difference was not statistically significant (Fig. 9).

\section{Loss of Kyphosis Correction in the Affected Segment}

The loss of kyphosis correction in the affected segment was calculated as the difference between the kyphotic angle immediately after surgery and that at the last follow-up visit. Five studies evaluated the loss of kyphosis correction. The summary effect was $0.38^{\circ}\left(95 \% \mathrm{CI}-0.40^{\circ}\right.$ to $1.18^{\circ} ; \mathrm{p}=0.33 ; \mathrm{I}^{2}=15.67$ ), which indicates a greater loss of kyphosis correction in the no-fusion group. However, a less than $1^{\circ}$ difference in correction loss suggests a clinically irrelevant effect (Fig. 10).

\section{Final Kyphosis in the Affected Segment}

The final kyphosis in the affected segment was calculated as the difference between the preoperative kyphotic angle and that at the final follow-up visit. Five studies evaluated the final kyphotic angle in the affected segment; the pooled average angle was $0.06^{\circ}$ higher in the no-fusion group (95\% CI $-1.13^{\circ}$ to $\left.1.25^{\circ} ; \mathrm{p}=0.92 ; \mathrm{I}^{2}=0\right)$ (Fig. 11).

\section{Height Correction of Fractured Vertebral Bodies}

Correction in the height of the fractured vertebral bodies was calculated as the difference between the pre- and 


\begin{tabular}{|c|c|c|c|c|c|c|c|}
\hline \multirow[t]{2}{*}{ Study name } & \multicolumn{7}{|c|}{ Statistics for each study } \\
\hline & $\begin{array}{l}\text { Difference } \\
\text { in means }\end{array}$ & $\begin{array}{l}\text { Standard } \\
\text { error }\end{array}$ & Variance & $\begin{array}{c}\text { Lower } \\
\text { limit }\end{array}$ & $\begin{array}{l}\text { Upper } \\
\text { limit }\end{array}$ & Z-Value & p-Value \\
\hline Chou, 2014 & 0.100 & 0.271 & 0.074 & -0.432 & 0.632 & 0.368 & 0.713 \\
\hline Dai, 2009 & 0.100 & 0.329 & 0.108 & -0.545 & 0.745 & 0.304 & 0.761 \\
\hline & 0.100 & 0.209 & 0.044 & -0.310 & 0.510 & 0.478 & 0.633 \\
\hline
\end{tabular}

\begin{tabular}{|c|c|c|c|c|c|c|c|}
\hline \multirow{2}{*}{ Study name } & & \multicolumn{6}{|c|}{$\underline{\text { Statistics for each study }}$} \\
\hline & $\begin{array}{l}\text { Difference } \\
\text { in means }\end{array}$ & $\begin{array}{l}\text { Standard } \\
\text { error }\end{array}$ & Variance & $\begin{array}{c}\text { Lower } \\
\text { limit }\end{array}$ & $\begin{array}{c}\text { Upper } \\
\text { limit }\end{array}$ & Z-Value & p-Value \\
\hline Chou, 2014 & -0.500 & 1.946 & 3.787 & -4.314 & 3.314 & -0.257 & 0.797 \\
\hline Jindal, 2012 & 19.720 & 5.783 & 33.441 & 8.386 & 31.054 & 3.410 & 0.001 \\
\hline \multirow[t]{2}{*}{ Tezeren, 2009} & -2.100 & 3.006 & 9.038 & -7.992 & 3.792 & -0.699 & 0.485 \\
\hline & 4.037 & 4.600 & 21.161 & -4.979 & 13.053 & 0.878 & 0.380 \\
\hline
\end{tabular}

FIG. 3. Forest plot for meta-analysis of the LBOS.
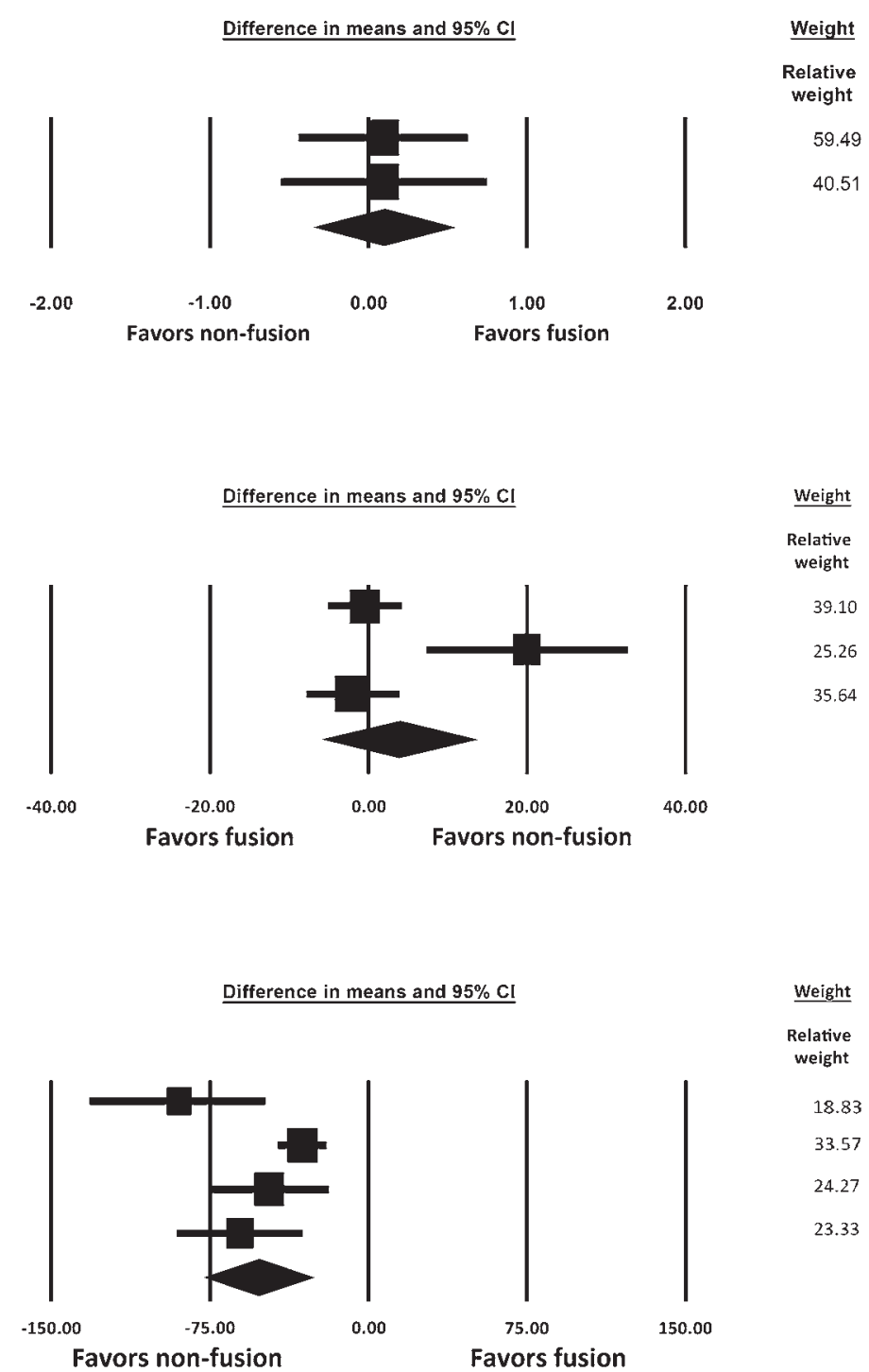

FIG. 4. Forest plot for meta-analysis of surgical time.

\begin{tabular}{|c|c|c|c|c|c|c|c|}
\hline \multicolumn{2}{|l|}{ Study name } & \multicolumn{6}{|c|}{ Statistics for each study } \\
\hline & $\begin{array}{l}\text { Difference } \\
\text { in means }\end{array}$ & $\begin{array}{c}\text { Standard } \\
\text { error }\end{array}$ & Variance & $\begin{array}{c}\text { Lower } \\
\text { limit }\end{array}$ & $\begin{array}{c}\text { Upper } \\
\text { Iimit }\end{array}$ & Z-Value & $\mathrm{p}$-Value \\
\hline Tezeren, 2009 & -228.600 & 42.806 & 1832.381 & $-3+2.499$ & -144.701 & $1-5.340$ & 0.000 \\
\hline Dai, 2009 & -113.300 & 14.948 & 223.450 & -142.598 & -84.002 & -7.579 & 0.000 \\
\hline Wang, 2006 & -269.000 & 74.466 & 5545.250 & -414.952 & -123.048 & $8-3.612$ & 0.000 \\
\hline \multirow[t]{2}{*}{ Jindal, 2012} & -108.500 & 46.128 & 2127.772 & -198.909 & -18.091 & -2.352 & 0.019 \\
\hline & -164.452 & 36.834 & 1356.754 & -236.646 & -92.259 & -4.465 & 0.000 \\
\hline
\end{tabular}

postoperative fractured vertebral body heights. The method of Mumford et al. ${ }^{18}$ was used. We found no significant difference between the groups $(0.60 \%$ [95\% CI $-4.47 \%$ to $3.25 \%$ ]; $\mathrm{p}=0.759 ; \mathrm{I}^{2}=0$ ) (Fig. 12).

\section{Risk of Bias}

Four studies used appropriate methods of randomization, and 1 was quasi-randomized on the basis of the order of hospital admission. None of the reports described alloca- 


\begin{tabular}{|c|c|c|c|c|c|c|c|}
\hline \multicolumn{2}{|l|}{ Study name } & \multicolumn{6}{|c|}{ Statistics for each study } \\
\hline \multicolumn{2}{|c|}{$\begin{array}{l}\text { Difference } \\
\text { in means }\end{array}$} & $\begin{array}{l}\text { Standard } \\
\text { error }\end{array}$ & Variance & $\begin{array}{l}\text { Lower } \\
\text { limit }\end{array}$ & $\begin{array}{c}\text { Upper } \\
\text { limit }\end{array}$ & Z-Value & p-Value \\
\hline Tezeren, 2009 & 0.600 & 0.864 & 0.747 & -1.094 & 2.294 & 0.694 & 0.487 \\
\hline Dai, 2009 & 1.100 & 1.144 & 1.308 & -1.141 & 3.341 & 0.962 & 0.336 \\
\hline \multirow[t]{2}{*}{ Wang, 2006} & 2.000 & 2.383 & 5.679 & -2.671 & 6.671 & 0.839 & 0.401 \\
\hline & 0.876 & 0.662 & 0.439 & -0.422 & 2.174 & 1.322 & 0.186 \\
\hline
\end{tabular}

FIG. 6. Forest plot for meta-analysis of hospital length of stay.

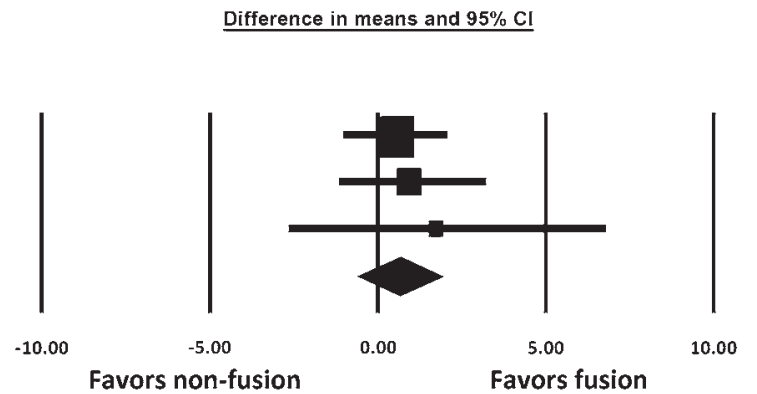

Weight

Relative

weight

58.74

33.53

7.72

\begin{tabular}{lcccccc} 
Study name & \multicolumn{5}{c}{ Statistics for each study } \\
\cline { 2 - 4 } & $\begin{array}{r}\text { Odds } \\
\text { ratio }\end{array}$ & $\begin{array}{c}\text { Lower } \\
\text { limit }\end{array}$ & $\begin{array}{c}\text { Upper } \\
\text { limit }\end{array}$ & Z-Value & p-Value \\
Tezeren, 2009 & 1.000 & 0.058 & 17.120 & 0.000 & 1.000 \\
Wang, 2006 & 0.720 & 0.156 & 3.314 & -0.422 & 0.673 \\
Jindal, 2012 & 0.457 & 0.039 & 5.409 & -0.622 & 0.534 \\
& 0.687 & 0.211 & 2.238 & -0.623 & 0.533
\end{tabular}

FIG. 7. Forest plot for meta-analysis of fixation system failure.

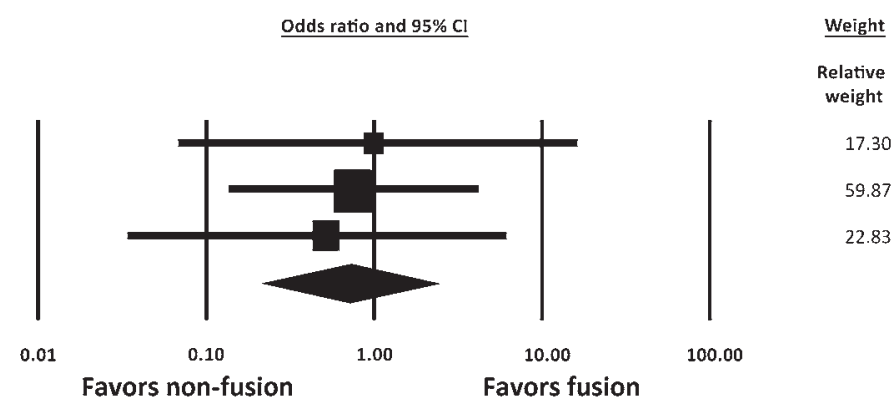

Odds ratio and $95 \% \mathrm{Cl}$

Weight

Relative weight

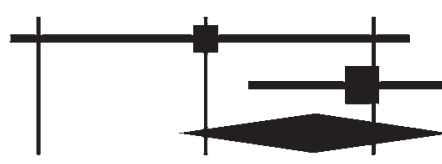

1.00

10.00

\subsection{9}

69.91

FIG. 8. Forest plot for meta-analysis of fixation system removal.

\begin{tabular}{lcccccccc} 
Study name & & \multicolumn{6}{c}{ Statistics for each study } \\
$\begin{array}{l}\text { Difference } \\
\text { in means }\end{array}$ & $\begin{array}{c}\text { Standard } \\
\text { error }\end{array}$ & Variance & $\begin{array}{r}\text { Lower } \\
\text { limit }\end{array}$ & $\begin{array}{c}\text { Upper } \\
\text { limit }\end{array}$ & Z-Value & p-Value \\
Tezeren, 2009 & 1.300 & 0.743 & 0.552 & -0.156 & 2.756 & 1.750 & 0.080 \\
Jindal, 2012 & -1.380 & 2.551 & 6.508 & -6.380 & 3.620 & -0.541 & 0.589 \\
Dai, 2009 & 0.600 & 1.826 & 3.335 & -2.979 & 4.179 & 0.329 & 0.742 \\
Chou, 2014 & -0.600 & 1.985 & 3.940 & -4.491 & 3.291 & -0.302 & 0.762 \\
& 0.862 & 0.630 & 0.397 & -0.373 & 2.097 & 1.368 & 0.171
\end{tabular}

tion-concealment methods; thus, they were all considered to be at uncertain risk for bias. Because of the surgical nature of the studies, it was impossible to perform blinding of the participants in all the studies, and this was considered a high-risk domain for all studies. Outcome blinding was reported for just 2 trials, and so they were considered to be at low risk for bias, whereas the risk of bias in the remaining studies was uncertain. All the studies were considered to be at low risk for selective reporting. The methodological quality assessment of all included trials is shown in Fig. 13. 


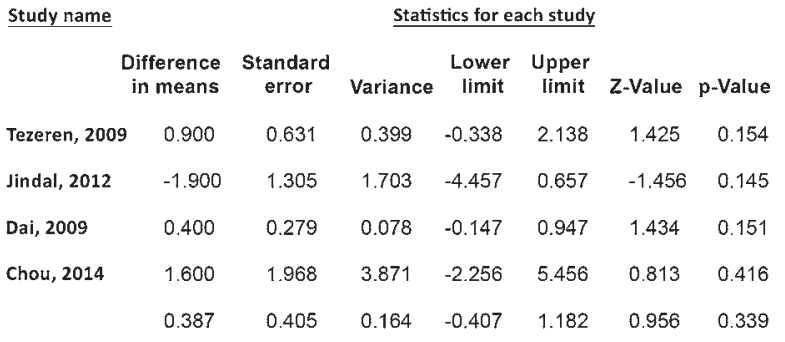

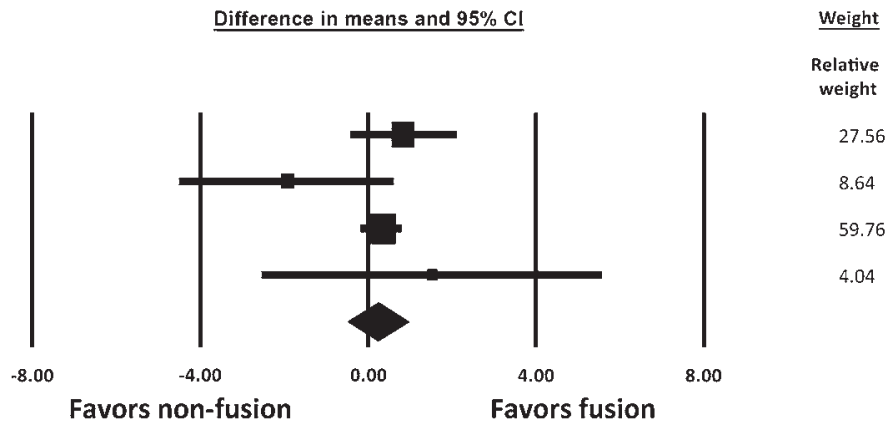

FIG. 10. Forest plot for meta-analysis of loss of kyphosis correction.

\begin{tabular}{|c|c|c|c|c|c|c|c|}
\hline \multirow[t]{2}{*}{ Study name } & & \multicolumn{6}{|c|}{$\underline{\text { Statistics for each study }}$} \\
\hline & $\begin{array}{l}\text { Difference } \\
\text { in means }\end{array}$ & $\begin{array}{c}\text { Standard } \\
\text { error }\end{array}$ & Variance & $\begin{array}{c}\text { Lower } \\
\text { limit }\end{array}$ & $\begin{array}{c}\text { Upper } \\
\text { limit }\end{array}$ & Z-Value & p-Value \\
\hline Tezeren, 2009 & 0.400 & 0.701 & 0.491 & -0.973 & 1.773 & 0.571 & 0.568 \\
\hline Jin dal, 2012 & 0.520 & 2.651 & 7.027 & -4.676 & 5.716 & 0.196 & 0.844 \\
\hline Dai, 2009 & -0.800 & 1.838 & 3.378 & -4.403 & 2.803 & -0.435 & 0.663 \\
\hline \multirow[t]{2}{*}{ Chou, 2014} & -2.200 & 2.109 & 4.449 & -6.334 & 1.934 & -1.043 & 0.297 \\
\hline & 0.058 & 0.609 & 0.370 & -1.134 & 1.251 & 0.096 & 0.924 \\
\hline
\end{tabular}

FIG. 11. Forest plot for meta-analysis of final kyphotic angle.

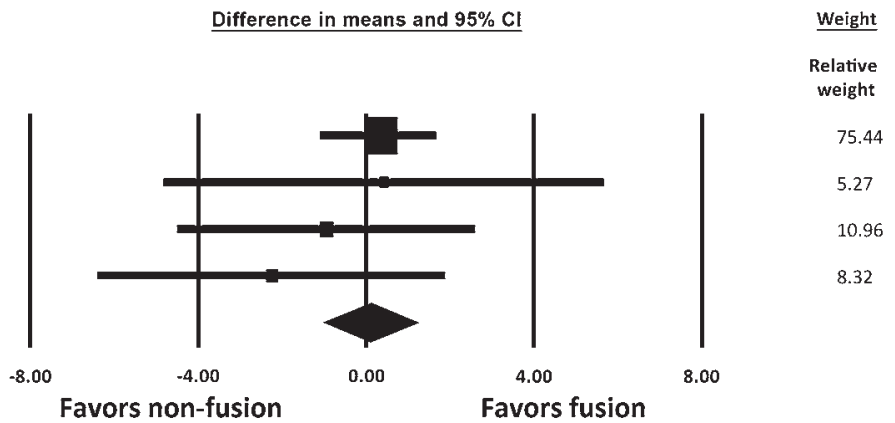

Weight

elative

75.44

5.27

10.96

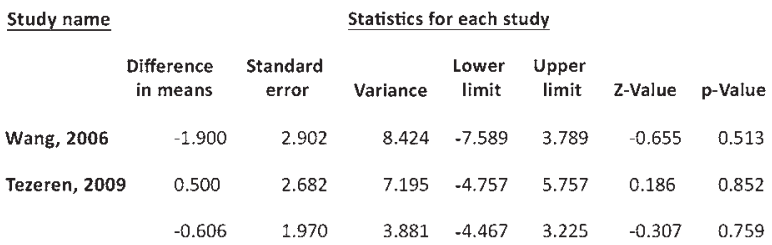

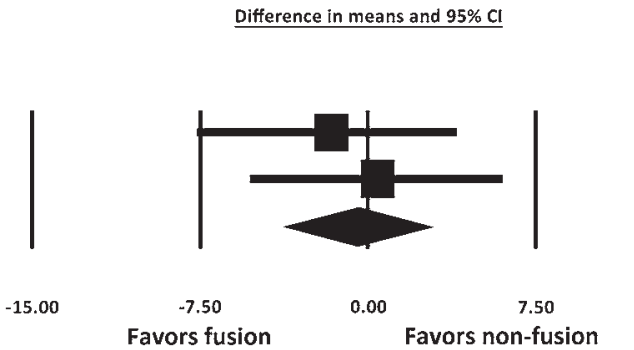

FIG. 12. Forest plot for meta-analysis of vertebral body height correction.

\section{Discussion}

Treatment of thoracolumbar burst fractures has been the subject of extensive discussion, and a number of conflicting proposals exist in the literature..$^{2,14,15,20}$ Among the available surgical approaches, fixation with arthrodesis is still considered by many authors to be the gold standard for correcting this type of trauma. Arthrodesis is an additional step in the procedure usually believed to be necessary for satisfactory long-term results. Those who advocate it propose that fusion protects the metal fixation systems and prevents fatigue of the material subjected to movement cycles throughout the patient's life.

The value of adjuvant fusion for spinal fixation has been questioned. Some studies that compared surgical treatment of thoracolumbar burst fractures with fusion and surgical treatment without fusion pointed to similar results between groups. We found 5 reports in the litera- ture of randomized or quasi-randomized studies ${ }^{5,6,13,22,25}$ that were designed to answer this question. Among them, 4 were randomized and 1 was quasi-randomized. A total of 220 patients were evaluated, and the average follow-up period was 69.1 months. This follow-up time seemed sufficient to reveal treatment failures that resulted from a lack of arthrodesis.

Most studies used the VAS for pain or LBOS instruments as a method for measuring functional differences. In this review, the clinical outcome results were not different between the groups.

Another clinical advantage of posterior instrumentation without fusion might be the avoidance of autogenous bone graft donor site-related complications. Most of the patients who underwent fusion complained of postsurgical pain that would compromise their mobility.

Regarding outcomes related to the surgical procedure, both surgical time and amount of intraoperative bleeding 


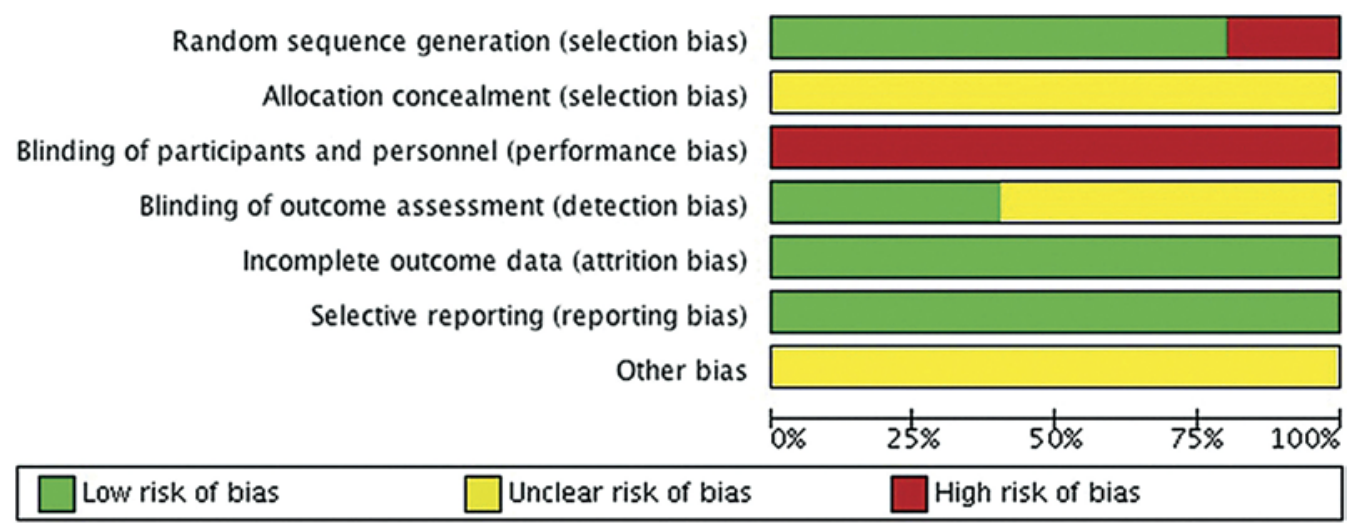

FIG. 13. Risk of bias assessment. Figure is available in color online only.

were significantly lower in the no-fusion group $(p<0.01)$. We found no difference in the lengths of hospital stay $(\mathrm{p}=$ $0.186)$. Tezeren et al. ${ }^{22}$ reported shorter surgical time and less intraoperative blood loss for their no-fusion group but no significant difference in the hospital lengths of stay between groups. Wang et al. ${ }^{25}$ also found significantly better results in their no-fusion group.

Failures of the fixation system, including fracture, dislocation, and screw loosening, were not different between groups. Sanderson et al. ${ }^{21}$ described a $14 \%$ system-failure rate in their no-fusion group, a result similar to that of the series that indicated an association between fusion and the transpedicular screw. ${ }^{22}$ Tezeren and $\mathrm{Kuru}^{23}$ reported that the failure rate is considerably lower when a long, rather than a short, fixation is performed, but concerning its association with fusion, no difference was apparent between the groups. ${ }^{24}$

In our review, implant removals that resulted from system failure were evaluated. ${ }^{4,21}$ The odds ratio for removal of a fixation system was 4.09 higher in the no-fusion group than in the fusion group; however, a sensitivity analysis in a study by Chou et al. ${ }^{5}$ found a high relative weight. The evaluation of this variable was also limited because part of the system removal described in the trials was found to be related to cultural factors and not failure only. ${ }^{5,25}$

Regarding the radiological outcomes, segmental motion in the fractured levels was evaluated in 2 studies. 5,25 These data suggest that mobility was preserved in the nofusion group, even after 10 years of follow-up, without reaching instability.

The loss of kyphosis correction had a better result in the fusion group, but the difference was not statistically significant, and its magnitude suggests that this effect is clinically irrelevant. Other authors reported that the average loss of kyphotic angle was not significantly different between groups. ${ }^{6,13}$ Defino and Canto ${ }^{8}$ reported progressive kyphosis at the final follow-up visit even when instrumentation was associated with fusion and pointed out that progressive kyphosis might be inevitable despite fusion. Mumford et al. ${ }^{18}$ pointed out that residual deformity did not correlate with symptoms at follow-up.

No significant difference was observed in the degree of kyphosis correction or in the final kyphotic angle, al- though the degree of kyphosis correction favored the nofusion group.

The appearance of data suggesting the absence of clinical or radiological benefit with fusion associated with internal fixation in the treatment of burst fractures highlights the possibility of treating these injuries with less invasive procedures. In this context, the use of percutaneous pedicle screws is gaining popularity as a therapeutic alternative. Less morbidity would result if victims of trauma were treated with percutaneous pedicle screws, and the results would be the same as those of open surgery. Percutaneous pedicle screws have been used by some authors and were found to have satisfactory results. ${ }^{15,19}$

\section{Conclusions}

We found no clear clinical benefit of arthrodesis as evaluated by the VAS and LBOS. Surgical time and intraoperative blood loss were significantly lower in the nofusion group. We found no difference in hospital lengths of stay, and the fixation-system failure rate did not differ between the groups. The no-fusion patients had greater mobility in their fractured segment. For the other radiological parameters, performing arthrodesis resulted in no significant difference. These results raise questions about the real need for fusion in the treatment of thoracolumbar burst fractures.

\section{References}

1. Avanzi O, Landim E, Meves R, Caffaro MF, de Albuquerque Araujo Luyten F, Faria AA: Thoracolumbar burst fracture: load sharing classification and posterior instrumentation failure. Rev Bras Ortop 45:236-240, 2010

2. Avilés C, Flores S, Molina M: Conservative versus operative treatment for thoracolumbar burst fractures without neurologic deficit. Medwave 16 (Suppl 1):e6383, 2016

3. Bazan PL, Borri AE, Torres PU, Consentino JS, Games MH: [Classification of thoracolumbar fractures: comparison between AO and Vaccaro classifications.] Coluna/Columna 9:165-170, 2010 (Portuguese)

4. Chou PH, Ma HL, Liu CL, Wang ST, Lee OK, Chang MC, et al: Is removal of the implants needed after fixation of burst fractures of the thoracolumbar and lumbar spine without fusion? A retrospective evaluation of radiological and functional outcomes. Bone Joint J 98-B:109-116, 2016 
5. Chou PH, Ma HL, Wang ST, Liu CL, Chang MC, Yu WK: Fusion may not be a necessary procedure for surgically treated burst fractures of the thoracolumbar and lumbar spines: a follow-up of at least ten years. J Bone Joint Surg Am 96:1724-1731, 2014

6. Dai LY, Jiang LS, Jiang SD: Posterior short-segment fixation with or without fusion for thoracolumbar burst fractures. A five to seven-year prospective randomized study. J Bone Joint Surg Am 91:1033-1041, 2009

7. de Assunçao Filho CAA, Veloso RP, Meves R, Bergamaschi JP, Caffaro FS, Avanzi O: Thoracolumbar burst fractures: radiographic evaluation on differences between Margerl's A and B. Acta Ortop Bras 20:240-242, 2012

8. Defino HL, Canto FR: Low thoracic and lumbar burst fractures: radiographic and functional outcomes. Eur Spine J 16:1934-1943, 2007

9. Greenough CG, Fraser RD: Assessment of outcome in patients with low-back pain. Spine (Phila Pa 1976) 17:36-41, 1992

10. Higgins JPT, Green S (eds): Cochrane Handbook for Systematic Reviews of Interventions, Version 5.1.0. London: The Cochrane Collaboration, 2011 (http://handbook. cochrane.org) [Accessed June 22, 2017]

11. Holdsworth F: Fractures, dislocations and fracture-dislocations of spine. J Bone Joint Surg [Br] 45:6-20, 1963

12. Hwang JH, Modi HN, Yang JH, Kim SJ, Lee SH: Short segment pedicle screw fixation for unstable T11-L2 fractures: with or without fusion? A three-year follow-up study. Acta Orthop Belg 75:822-827, 2009

13. Jindal N, Sankhala SS, Bachhal V: The role of fusion in the management of burst fractures of the thoracolumbar spine treated by short segment pedicle screw fixation: a prospective randomised trial. J Bone Joint Surg Br 94:1101-1106, 2012

14. Kumar A, Aujla R, Lee C: The management of thoracolumbar burst fractures: a prospective study between conservative management, traditional open spinal surgery and minimally interventional spinal surgery. SpringerPlus 4:204, 2015

15. Lee JK, Jang JW, Kim TW, Kim TS, Kim SH, Moon SJ: Percutaneous short-segment pedicle screw placement without fusion in the treatment of thoracolumbar burst fractures: is it effective?: comparative study with open short-segment pedicle screw fixation with posterolateral fusion. Acta Neurochir (Wien) 155:2305-2312, 2013

16. Lee JY, Vaccaro AR, Lim MR, Oner FC, Hulbert RJ, Hedlund $\mathrm{R}$, et al: Thoracolumbar injury classification and severity score: a new paradigm for the treatment of thoracolumbar spine trauma. J Orthop Sci 10:671-675, 2005

17. Liberati A, Altman DG, Tetzlaff J, Mulrow C, Gøtzsche PC, Ioannidis JPA, et al: The PRISMA statement for reporting systematic reviews and meta-analyses of studies that evaluate health care interventions: explanation and elaboration. PLoS Med 6:e1000100, 2009
18. Mumford J, Weinstein JN, Spratt KF, Goel VK: Thoracolumbar burst fractures. The clinical efficacy and outcome of nonoperative management. Spine (Phila Pa 1976) 18:955-970, 1993

19. Palmisani M, Gasbarrini A, Brodano GB, De Iure F, Cappuccio M, Boriani L, et al: Minimally invasive percutaneous fixation in the treatment of thoracic and lumbar spine fractures. Eur Spine J 18 (Suppl 1):71-74, 2009

20. Sadatsune DA, da Costa PP, Caffaro MFS, Umeta RS, Meves R, Osmar A: Thoracolumbar burst fractures: correlation between residual kyphosis and function after surgery. Rev Bra Ortop 47:474-478, 2012

21. Sanderson PL, Fraser RD, Hall DJ, Cain CM, Osti OL, Potter GR: Short segment fixation of thoracolumbar burst fractures without fusion. Eur Spine J 8:495-500, 1999

22. Tezeren G, Bulut O, Tukenmez M, Ozturk H, Oztemur Z, Ozturk A: Long segment instrumentation of thoracolumbar burst fracture: fusion versus nonfusion. J Back Musculoskeletal Rehabil 22:107-112, 2009

23. Tezeren G, Kuru I: Posterior fixation of thoracolumbar burst fracture: short-segment pedicle fixation versus long-segment instrumentation. J Spinal Disord Tech 18:485-488, 2005

24. Tisot RA, da Silveira Vieira J, dos Santos RT, Badotti AA, da Silva Collares D, Stumm LD, et al: Burst fracture of the thoracolumbar spine: correlation between kyphosis and clinical result of the treatment. Coluna/Columna 14:129-133, 2015

25. Wang ST, Ma HL, Liu CL, Yu WK, Chang MC, Chen TH: Is fusion necessary for surgically treated burst fractures of the thoracolumbar and lumbar spine?: a prospective, randomized study. Spine (Phila Pa 1976) 31:2646-2653, 2006

\section{Disclosures}

The authors report no conflict of interest concerning the materials or methods used in this study or the findings specified in this paper.

\section{Author Contributions}

Conception and design: both authors. Acquisition of data: both authors. Analysis and interpretation of data: both authors. Drafting the article: both authors. Critically revising the article: both authors. Reviewed submitted version of manuscript: both authors. Approved the final version of the manuscript on behalf of both authors: Botelho. Statistical analysis: both authors. Administrative/technical/material support: both authors. Study supervision: both authors.

\section{Correspondence}

Ricardo V. Botelho, Department of Neurosurgery, Hospital do Servidor Público do Estado de São Paulo, Tuim 525, Apto 122A, São Paulo 040-102, Brazil. email: bitbot@uol.com.br. 